\title{
Wer kümmert sich ums Internet?
}

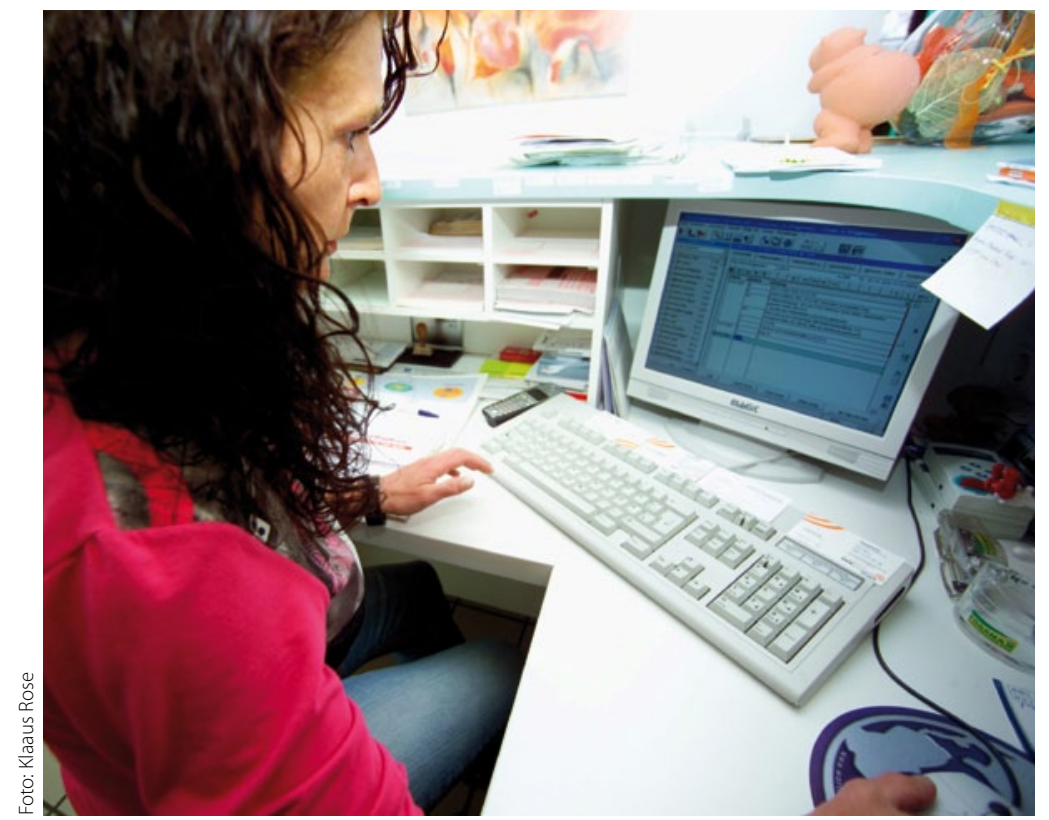

Besonders von den MFA werden immer mehr PC-Kenntnisse erwartet.

\section{Von der e-Mail-Kommunikation bis zur Organisation von Recall-Aktio- nen: Für MFA bringt die Internet- Anbindung der Arztpraxen eine Fülle neuer Aufgaben mit sich. Diese Tätigkeiten sollten im Team genau besprochen und verteilt werden.}

- Das Internet mit all seinen Chancen und Tücken bestimmt zunehmend den Arbeitsalltag auch in der Praxis des niedergelassenen Arztes. E-Mails werden geschrieben, die Abrechnung mit der KV geschieht online, immer mehr Praxen gehen zur Online-Terminvergabe über - das sind nur drei Beispiele für die Anwendung der neuen Medien in Arztpraxen. Es empfiehlt sich, dass eine dafür kompetente MFA diesen neuen Aufgabenbereich vorherrschend über- nimmt. Art und Umfang der erforderlichen Tätigkeiten sollten nicht nur vorab genau besprochen, sondern auch in der Stellenbeschreibung schriftlich detailliert fixiert werden.

\section{Handlungsanweisungen festlegen}

Folgende Punkte können zum Beispiel genannt werden:

- Verantwortlichkeit für die e-MailKommunikation und die „Web-Netikette" der Arztpraxis mit den Patienten,

- Organisation von Recall-Aktionen, auch per SMS,

- Digitale Präventionsassistenz: interaktive Anwendungen und individualisierte Orientierungshilfen über Smartphones (Apps), zum Beispiel zur Motivation von Patienten zur Prävention,

- Unterstützung des Arztes bei einer te-
Praxiskosten

\section{Das verdienen junge MFA}

Medizinische Fachangestellte (MFA)

werden nach der Ausbildung in Hamburg, Hessen und Bayern am besten bezahlt. Dabei winkt den Berufseinsteigerinnen in Hessen mit im Schnitt 22093 Euro das höchste Jahresgehalt. In Hamburg bekommen sie immerhin noch ein Jahresgehalt von 20769 Euro und in Bayern von 20399 Euro. Das zeigt eine Studie des Internet-Portalbetreibers PersonalMarkt Services $\mathrm{GmbH}$, bei der die Gehaltsdaten von 5526 MFA aus neun Bundesländern ausgewertet wurden. Das niedrigste Einstiegsgehalt gibt es demnach mit 17942 Euro in Brandenburg.

REH

lemedizinischen Sprechstunde (etwa zur Schrittmacherkontrolle),

- Planung des Fortbildungskalenders für das Praxisteam mit Hilfe von Kongresskalendern im Internet, und - Aufbau und Pflege der Praxis-Website in Abstimmung mit den strategischen Zielen der Praxis.

Zunächst sollte in einer Teambesprechung geklärt werden, welche Ziele die Praxisleitung umsetzen möchte. Die geplanten Aktivitäten wie Imagepflege oder Ansprache neuer Zielgruppen sollten dann kontrolliert werden, etwa durch die Zahl der Page-Impressions, d.h. der Besucher der Homepage.

THERESIA WÖLKER =

- Theresia Wölker, Bendorf, ist Personaltrainerin und Beraterin für Praxisteams. 